\title{
Extracorporeal shock wave therapy in the treatment of calcific tendinopathy of the shoulder: the ASSERT database
}

\author{
Gayle Maffulli1 \\ Enzo Iuliano ${ }^{2}$ \\ Johnny Padulo 2,3 \\ Ludger Gerdesmeyer 4 \\ Jan Rompe ${ }^{5}$ \\ Nicola Maffulli6,7 \\ 1 Wholelife Clinics, London, UK \\ 2 University eCampus, Novedrate, Italy \\ 3 Faculty of Kinesiology, University of Split, Split, \\ Croatia \\ 4 Department of Orthopaedic Surgery and Traumatol- \\ ogy, University Schlswig, Holstein, Campuskiel, Keil, \\ Germany \\ 5 OrthoTrauma Evaluation Institute, Mainz, Germany \\ 6 Department of Musculoskeletal Disorders, Faculty of \\ Medicine and Surgery, University of Salerno, \\ Salerno, Italy \\ 7 Centre for Sports and Exercise Medicine, Barts and \\ the London School of Medicine and Dentistry, Mile \\ End Hospital, London, UK
}

\section{Corresponding author:}

Nicola Maffulli

Department of Musculoskeletal Disorders

School of Medicine and Surgery

University of Salerno,

Mary University of London

Barts and the London School of Medicine and Dentistry

Centre for Sports and Exercise Medicine

Mile End Hospital 275 Bancroft Road

E1 4DG, London, England, UK

Tel.: +447989358279

E-mail:n.maffulli@qmul.ac.uk

\section{Summary}

Introduction: This study aimed to determinate the effectiveness of extracorporal shock wave therapy (ESWT) in the treatment of calcific tendinopathy of the shoulder (CTS) in both the short and long term.

Methods: Participants of this study were recruited by different clinicians of the National Health Service (NHS) and private sector centres in the United Kingdom. Data were collected in a web-based database [Assessment of the Effectiveness of Ex- tracorporeal Shock Wave Therapy (ESWT) for Soft Tissue Injuries (ASSERT)]. The 15 participants (mean age $49.00 \pm 20.04 \mathrm{y}$ ) were treated using a standardized ESWT protocol. At baseline and again at 3, 6, 12 and 24 months following ESWT treatment, the participants were evaluated with the Visual Analogue Scale (VAS) for pain perception, the Upper Extremity score for functional limitation assessment, and the 6 scores of EuroQol5D questionnaire (EQ-5D) for quality of life.

Results: There was a significant improvement over time in 1 of the 8 analysed scores, the EQ-5D Thermometer Score $(p=0.002)$.

Conclusion: ESWT showed beneficial effects on the global health score over a 24-month follow-up period.

Level of evidence: IV.

KEY WORDS: calcific tendinopathy of the shoulder, extracorporeal shock wave therapy, longitudinal study.

\section{Introduction}

Shoulder pain is one of the most frequent musculoskeletal pathologies with a prevalence of between 4 and $26 \%{ }^{1}$. Calcific tendonitis of the shoulder (CTS) is a painful condition which can be acute and chronic in nature. The cause of calcific tendinopathy is still not understood. It has been said to occur due to degenerative lesions of the rotator cuff ${ }^{2}$ and as a result of the deposition of calcium in the tissues followed by spontaneous resorption of the calcific deposit ${ }^{3}$. Patients with CTS present with severe, disabling pain which occurs usually in the morning and can be associated with stiffness similar to that of a frozen shoulder ${ }^{4}$. The initial treatment for CTS is usually conservative management including rest, analgesics, nonsteroidal and anti-inflammatory medicines and a subacromial bursal corticosteroid injections with resolution of symptoms in $90-99 \%$ of cases, thereby making surgery an exceptional indication ${ }^{5-7}$. However, it has been identified that in many cases the initial improvement deteriorates and the condition becomes chronic ${ }^{8}$. ESWT has emerged as an appropriate treatment for CTS when conservative measures have failed and its efficacy and safety have been well documented ${ }^{5,9-14}$ with success rates ranging from 78 to $91 \%^{10,15-23}$. The long term benefits of ESWT for CTS have also been 
reported 2 years post ESWT ${ }^{14,24}$ with corresponding imaging showing elimination of calcium deposits in the short term at 12 weeks post ESWT ${ }^{25,26}$ and also in the longer term at 2-3 years post ESWT ${ }^{14}$. Shockwave therapy has been reported to provide equal or better results than surgery for CTS ${ }^{13}$.

This study aimed to evaluate the overall effectiveness of the ESWT in (1) reducing the clinical severity of symptoms, (2) relieving the pain symptom and (3) improving the quality of life of patients with chronic calcific tendinopathy of the shoulder over a period of 24 months. Furthermore, this study also aimed to analyse if differences existed between male and female patients on the effects of ESWT on these three variables, and again if age and involvement in previous treatments could have played a role in the effectiveness of ESWT.

\section{Materials and methods}

The ASSERT database was used to collect information on the effectiveness of ESWT across the United Kingdom. The ESWT machines were standardised and a standardised treatment protocol, together with standardised baseline measurements and outcome measures and time points in centres across the United Kingdom, were adopted to aid validity ${ }^{27}$.

\section{Recruitment}

Participants were recruited from both the National Health Service (NHS) and private sector centres in the United Kingdom. Clinicians recruited participants presenting with calcific tendinopathy of the shoulder, and for whom ESWT was indicated as the treatment choice.

\section{Participants}

Participants were included if they were over the age of 18 , had a diagnosis of CTS confirmed by the recruiting clinician; undergone a course of conservative therapy which had not been effective in relieving symptoms; been recommended to receive ESWT at one of the recruiting centres; not been diagnosed with inflammatory arthropathy; and demonstrated the ability to give informed consent.

A total of 23 participants were enrolled (16 males; 7 females) and 15 participants (11 males and 4 females) met all the inclusion criteria and were considered for analysis (Tab. I).
This study has been designed and conducted in accordance with the principles of the Declaration of Helsinki and it has been approved by the Local Ethics Committee (11/LO/0253). A written informed consent was obtained by each participant ${ }^{28}$.

\section{Use of ESWT machine}

Standardisation of the machine and the process of administration of ESWT had been agreed to ensure consistency, reproducibility and generalisability of the results. All clinicians using the Swiss DolorClast device (Electro Medical Systems SA, Nyon, Switzerland) and Stortz devices (Stortz Medical AG, Tägerwilen, Switzerland) received training and certification to ensure adherence to the protocol. All clinicians followed a standardised method of administration of ESWT29. This included delivering an initial 500 "warm-up" impulses at a low air pressure (1.5 bar of air pressure). This reduces the pain which patients experience during treatment. Based on patient feedback, the clinician then increased the air pressure to 2.5 bar or above. The total dose of impulses remained constant at 2500 per session, with one session a week for three planned consecutive weeks, with a maximum gap between two consecutive treatments of two weeks.

\section{Database}

The ASSERT database is a web based system (www.assert.org.uk) from which the clinician received a study number for each participant ${ }^{27}$. Only unidentifiable information with the patients' study number was entered into the database. Sensitive data are held on secure servers. Following informed consent, the clinician recorded the following information: (1) Diagnosis: this was formulated on clinical grounds and some clinicians also used imaging to confirm the diagnosis; (2) Area treated/condition presented with; (3) Date of presentation of symptoms; (4) Date of treatment of ESWT; (5) Code for clinicians centre; (6) Centre where treatment was administered; (7) Previous treatments prior to consultation; (8) Side treated; (9) Dates when ESWT was administered; (10) Baseline scores recorded: EuroQol questionnaire scores (EQ$5 D)^{30}$, Visual Analogue Scale for pain (VAS) ${ }^{31}$, and Upper Extremity Function Score (UPP-EST) ${ }^{32}$; (11) Follow-up scores at 3, 6, 12 and 24 months post treatment; (12) Satisfaction: rated poor, satisfactory, good or excellent; (13) Time to effective treatment; (14) Recurrence of the condition; (15) Complications; and (16) Adverse events.

Table I. Sample of participants.

\begin{tabular}{llll}
\hline & $\mathbf{n}$ & Age $(\mathbf{y})$ & $\begin{array}{l}\text { Number of previous } \\
\text { treatments }\end{array}$ \\
\hline Participants enrolled & $23(16$ males and 7 females $)$ & $52.27 \pm 20.23$ & $1.60 \pm 1.17$ \\
\hline $\begin{array}{l}\text { Participants considered } \\
\text { for the analyses }\end{array}$ & $15(11$ males and 4 females $)$ & $49.00 \pm 20.04$ & $1.63 \pm 1.06$ \\
\hline
\end{tabular}




\section{Baseline and follow-up assessments}

After having obtained written informed consent, the treating clinician undertook baseline assessments. The follow-up assessments were instead performed after 3, 6, 12 and 24 months' post treatment. The coordinators of ASSERT undertook all follow-up assessments via email, telephone or post.

\section{Outcome assessment}

The EQ-5D ${ }^{30}$, the VAS for pain ${ }^{31}$ and the Upper Extremity Function Score ${ }^{32}$ were completed by the participants of the study.

The EQ-5D is a standardised measure of health status developed by the EuroQol Group to provide a simple, generic measure of health for clinical and economic appraisal. For the present study, the version $3 L(E Q-5 D-3 L)$ was used. This is a simple questionnaire composed of 5 items with a 3-point scale answer for each item, and designed for completion by the person being treated. Each one of the 5 items respectively investigates 5 dimensions of the quality of life, namely (1) mobility, (2) self-care, (3) usual activities, (4) pain/discomfort, and (5) anxiety/depression. A score from 1 (best score) to 3 (worst score) is assigned for each dimension. The EQ-5D also includes a scale, named EQ-5D Thermometer Scale, that allows obtaining a global score to generally describe the quality of life of the patient. It consists in a vertical line, $100 \mathrm{~mm}$ in length, anchored by 2 word descriptors at each end, which are "the worst health you can imagine" and "the best health you can imagine". Patients are asked to mark on the line the point which they feel represents their perception of their current health status. The score ranges from 0 (worst health status) to 100 (best health status), and it is computed by measuring the distance (in $\mathrm{mm}$ ) between the end of the line marked with "the worst health you can imagine" and the mark on the line indicated by the patient.

The VAS for pain is very similar to the EQ-5D Thermometer Scale, but it focuses only on the pain perceived by the patient, not on the overall quality of life. It consists in a horizontal line, $100 \mathrm{~mm}$ in length, which asks the patients "How severe is your pain today?". The line is anchored by 2 word descriptors at each end, which are "no pain" and "very severe pain". Also in this case, patients mark on the line the point which they feel represents their current perception of their pain intensity. The score, from 0 (no pain) to 100 (very severe pain), is computed as the measurement of the distance (in $\mathrm{mm}$ ) between the end of the line marked with "no pain" and the point on the line indicated by the patient.

The Upper Extremity Function Scale developed by Pransky et al. ${ }^{32}$ is a self-administered questionnaire which can be used to measure the impact of upper extremity disorders on a person's ability to perform physical tasks. It can be used to monitor the patient over time both to detect worsening of the condition due to occupational exposure and to assess response to therapeutic interventions. The maximum score is 80 and the minimum is 8 . The lower the score the better the condition.

\section{Statistical analysis}

Linear Mixed Model analysis (LMM) with maximum likelihood method was performed in order to evaluate the significant effects over time produced by ESWT in the treatment of the CTS. To perform the LMM analysis, the Time factor (fixed factor: T0 vs T3 vs T6 vs T12 vs T24) was used to investigate differences over time. The VAS and the UPP-EXT scores, as well as the 6 scores of the EQ-5D were considered as dependent variables for the analysis. If two or more of the follow-up datasets were missing the patient was excluded.

Due to the multiple dependent variables, the Bonferroni correction was used adjust the $p$-value. The Bonferroni correction indicate an adjusted $p<0.006$ for significance. When a significant effect over time was detected, Bonferroni post-hoc analysis (adjusted for multiple comparison) was used to perform comparisons in pair among the different time of assessments.

All the analyses were performed with the statistical software SPSS 20 (IBM Corporation, Chicago, IL, USA).

\section{Results}

There was no significant change over time for the VAS score $\left(F_{4,24}=2.509 ; p=0.069\right)$.

Similarly, there was no significant change over time $\left(F_{4,17}=2.559 ; p=0.073\right)$ for the UPP-EXT score. The $E Q-5 D$ questionnaire showed no significant difference over time for the EQ-5D Anxiety/Depression ( $F$ not computable $\mathrm{p}=1.000)$; the $E Q-5 D$ Mobility score $\left(F_{4,18}=1.238 ; p=0.327\right)$; the EQ-5D Pain/Discomfort score $\left(F_{4,21}=3.230 ; p=0.032\right.$; not significant due to the Bonferroni correction); the EQ-5D Usual Activities score $\left(F_{4,14}=2.192 ; p=0.121\right)$; and the $E Q-5 D$ SelfCare $\left(F_{4,16}=0.471 ; p=0.756\right)$. Conversely, a significant increase (improvement) over time was found in the EQ-5D Thermometer Scale $\left(F_{4,1}=6.821 ; p<0.002\right)$. In order to have more clarity, all the data are reported as Means \pm SD in Table II with the results of the posthoc analysis.

\section{Discussion}

Conservative methods for treating refractory calcific tendinopathy of the shoulder have been shown to have limited efficacy with the true effectiveness being unknown ${ }^{1}$. Several studies have confirmed the benefits of ESWT for the treatment of CTS $5,15,33$ and a systematic review in 2011 found moderate evidence supporting the use of focused ESWT ${ }^{34}$. There have been discussions around whether high energy ESWT is more effective than low energy, with some advocating high energy 20,35 reporting better function and pain re- 
Table II. Results relative to the effects over time with the post-hoc analyses outputs.

\begin{tabular}{|c|c|c|c|c|c|c|c|c|}
\hline \multirow[t]{2}{*}{ Tests } & & \multirow{2}{*}{$\begin{array}{l}\text { T0 } \\
\text { Means } \pm \\
\text { SD (N) }\end{array}$} & \multirow{2}{*}{$\begin{array}{l}\text { T3 } \\
\text { Means } \pm \\
\text { SD (N) }\end{array}$} & \multirow{2}{*}{$\begin{array}{l}\text { T6 } \\
\text { Means } \pm \\
\text { SD (N) }\end{array}$} & \multirow{2}{*}{$\begin{array}{l}\text { T12 } \\
\text { Means } \pm \\
\text { SD (N) }\end{array}$} & \multirow{2}{*}{$\begin{array}{l}\text { T24 } \\
\text { Means } \pm \\
\text { SD (N) }\end{array}$} & \multirow{2}{*}{$\begin{array}{l}\text { Overall } \\
\text { significance } \\
\text { in time }\end{array}$} & \multirow{2}{*}{$\begin{array}{l}\text { Comparisons } \\
\text { in pair - } \\
\text { significance }\end{array}$} \\
\hline & & & & & & & & \\
\hline \multirow[t]{2}{*}{ VAS } & Scores & $\begin{array}{l}51.64 \pm \\
18.11(11)\end{array}$ & $\begin{array}{l}48.57 \pm \\
27.16(7)\end{array}$ & $\begin{array}{l}52.13 \pm \\
36.07(8)\end{array}$ & $\begin{array}{l}16.25 \pm \\
13.00(4)\end{array}$ & $\begin{array}{l}36.33 \pm \\
28.11(3)\end{array}$ & \multirow[t]{2}{*}{$\begin{array}{l}\text { Not } \\
\text { significant }\end{array}$} & - \\
\hline & $\begin{array}{l}\text { Difference } \\
\text { with } \\
\text { baseline } \\
\text { score }\end{array}$ & - & -3.07 & +0.49 & -35.39 & -15.31 & & \\
\hline \multirow[t]{2}{*}{ UPP-EXT } & Scores & $\begin{array}{l}36.22 \pm \\
18.36(9)\end{array}$ & $\begin{array}{l}22.40 \pm \\
20.65(5)\end{array}$ & $\begin{array}{l}27.29 \pm \\
19.18(7)\end{array}$ & $\begin{array}{l}28.00 \pm \\
32.92(3)\end{array}$ & $\begin{array}{l}10.50 \pm \\
2.12(2)\end{array}$ & \multirow[t]{2}{*}{$\begin{array}{l}\text { Not } \\
\text { significant }\end{array}$} & \\
\hline & $\begin{array}{l}\text { Difference } \\
\text { with } \\
\text { baseline } \\
\text { score }\end{array}$ & - & -13.82 & -8.93 & -8.22 & -25.72 & & \\
\hline \multirow[t]{2}{*}{$\begin{array}{l}\text { EQ-5D } \\
\text { Anxiety/Depression }\end{array}$} & Scores & $\begin{array}{l}1.27 \pm \\
0.47(11)\end{array}$ & $\begin{array}{l}1.00 \pm 0.00 \\
\text { (5) }\end{array}$ & $\begin{array}{l}1.00 \pm 0.00 \\
(7)\end{array}$ & $\begin{array}{l}1.00 \pm 0.00 \\
(3)\end{array}$ & $\begin{array}{l}1.33 \pm 0.58 \\
\text { (3) }\end{array}$ & \multirow[t]{2}{*}{$\begin{array}{l}\text { Not } \\
\text { significant }\end{array}$} & - \\
\hline & $\begin{array}{l}\text { Difference } \\
\text { with } \\
\text { baseline } \\
\text { score }\end{array}$ & - & -0.27 & -0.27 & -0.27 & +0.06 & & \\
\hline \multirow[t]{2}{*}{ EQ-5D Mobility } & Scores & $\begin{array}{l}1.27 \pm \\
0.47(11)\end{array}$ & $\begin{array}{l}1.40 \pm 0.55 \\
\text { (5) }\end{array}$ & $\begin{array}{l}1.29 \pm 0.49 \\
(7)\end{array}$ & $\begin{array}{l}1.00 \pm 0.00 \\
(3)\end{array}$ & $\begin{array}{l}1.00 \pm 0.00 \\
\text { (3) }\end{array}$ & \multirow[t]{2}{*}{$\begin{array}{l}\text { Not } \\
\text { significant }\end{array}$} & - \\
\hline & $\begin{array}{l}\text { Difference } \\
\text { with } \\
\text { baseline } \\
\text { score }\end{array}$ & - & +0.13 & +0.02 & -0.27 & -0.27 & & \\
\hline \multirow[t]{2}{*}{$\begin{array}{l}\text { EQ-5D } \\
\text { Pain/Discomfort }\end{array}$} & Scores & $\begin{array}{l}1.73 \pm \\
0.47(11)\end{array}$ & $\begin{array}{l}1.80 \pm 0.84 \\
\text { (5) }\end{array}$ & $\begin{array}{l}2.29 \pm 0.49 \\
(7)\end{array}$ & $\begin{array}{l}1.67 \pm 0.58 \\
(3)\end{array}$ & $\begin{array}{l}1.33 \pm 0.58 \\
\text { (3) }\end{array}$ & \multirow[t]{2}{*}{$\begin{array}{l}\text { Not } \\
\text { significant }\end{array}$} & \multirow[t]{2}{*}{-} \\
\hline & $\begin{array}{l}\text { Difference } \\
\text { with } \\
\text { baseline } \\
\text { score }\end{array}$ & - & +0.07 & +0.56 & -0.06 & -0.40 & & \\
\hline \multirow[t]{2}{*}{$\begin{array}{l}\text { EQ-5D Usual } \\
\text { Activities }\end{array}$} & Scores & $\begin{array}{l}2.00 \pm \\
0.45(11)\end{array}$ & $\begin{array}{l}1.60 \pm 0.55 \\
(5)\end{array}$ & $\begin{array}{l}2.00 \pm 0.00 \\
(7)\end{array}$ & $\begin{array}{l}1.33 \pm 0.58 \\
(3)\end{array}$ & $\begin{array}{l}2.00 \pm 1.00 \\
(3)\end{array}$ & \multirow[t]{2}{*}{$\begin{array}{l}\text { Not } \\
\text { significant }\end{array}$} & \multirow[t]{2}{*}{-} \\
\hline & $\begin{array}{l}\text { Difference } \\
\text { with } \\
\text { baseline } \\
\text { score }\end{array}$ & - & -0.40 & 0.00 & -0.67 & 0.00 & & \\
\hline \multirow[t]{2}{*}{ EQ-5D Self-Care } & Scores & $\begin{array}{l}1.64 \pm \\
0.67(11)\end{array}$ & $\begin{array}{l}1.40 \pm 0.55 \\
\text { (5) }\end{array}$ & $\begin{array}{l}1.43 \pm 0.53 \\
(7)\end{array}$ & $\begin{array}{l}1.33 \pm 0.58 \\
(3)\end{array}$ & $\begin{array}{l}1.33 \pm 0.58 \\
\text { (3) }\end{array}$ & \multirow[t]{2}{*}{$\begin{array}{l}\text { Not } \\
\text { significant }\end{array}$} & \multirow[t]{2}{*}{-} \\
\hline & $\begin{array}{l}\text { Difference } \\
\text { with } \\
\text { baseline } \\
\text { score }\end{array}$ & - & -0.24 & -0.21 & -0.31 & -0.31 & & \\
\hline \multirow[t]{2}{*}{$\begin{array}{l}\text { EQ-5D } \\
\text { Thermometer Sc. }\end{array}$} & Scores & $\begin{array}{l}49.45 \pm \\
25.74(11)\end{array}$ & $\begin{array}{l}83.40 \pm \\
20.19(5)\end{array}$ & $\begin{array}{l}77.71 \pm \\
19.81(7)\end{array}$ & $\begin{array}{l}89.33 \pm \\
12.5(3)\end{array}$ & $\begin{array}{l}83.67 \pm \\
12.06(3)\end{array}$ & \multirow[t]{2}{*}{$p=0.002$ * } & \multirow[t]{2}{*}{$\begin{array}{l}\text { T0 vs T3, T6, } \\
\text { T12, T24 }\end{array}$} \\
\hline & $\begin{array}{l}\text { Difference } \\
\text { with } \\
\text { baseline } \\
\text { score }\end{array}$ & - & $+33,95$ & +28.26 & +39.88 & 34.22 & & \\
\hline
\end{tabular}

\footnotetext{
* $p$-value for significance after Bonferroni correction is $<0.006$.
} 
duction and others reporting similar improvements using low energy ESWT ${ }^{5}$. ESWT is now being considered a safe and minimally invasive treatment, with similar if not better results than surgery ${ }^{6}$. ESWT treatment avoids potential complications and expenditure associated with surgery. Dubs ${ }^{36}$ found that ESWT, in addition to proving to be more efficacious, was also much more cost effective, saving an average of $\$$ 2000 per patient. ESWT versus arthroscopy for rotator cuff calcification has been found to be $5^{37}$ to $6.4^{38}$ times less expensive.

The present study did not confirm the positive results of previous studies $5,15,33,34$. This may have been due to the small sample of patients $(n=15)$. At the time of recruitment, the insurance companies would not reimburse for the CTS and therefore the treatment was mot readily available to patients. No analysis is perfect, and we acknowledge that many other variables such as the amount of energy employed, high vs low intensity shock wave treatment, radial $v s$ focused shock wave treatment, the methods of localization of the shock waves, the number of shocks, and the number of sessions must also be considered when evaluating the efficacy of ESWT. We acknowledge that more high-quality and wellconducted studies are necessary. A database such as ASSERT could be a valid method for the systematic collection of large amount of data and for the standardization of procedures to obtain strong evidences in this field.

Concerning the limitations, this study is not a randomised controlled trial. Several studies have confirmed the benefits of ESWT for the treatment of CTS $5,15,33$ and a systematic review in 2011 found moderate evidence supporting the use of focused ESWT $^{34}$. The National Institute for Health and Clinical Excellence (NICE) suggested that the effectiveness of ESWT in "real life" would have needed to be evaluated in a pragmatic fashion, using standardised protocols and well validated clinically relevant outcome measures. The ASSERT protocol is NICE compliant, and satisfies the requirements set out by NICE ${ }^{39}$.

The fact that many different clinicians were involved in the treatment, after appropriate certified training and standardisation of the protocol, and that the effects of treatment were evaluated by independent individuals, increases the generalizability of the present findings, and, in this respect, should be considered a major strength of the present study.

In conclusion, when administered in a standardised fashion to an unselected population of patients suffering from calcific tendinopathy of the shoulder, ESWT therapy is safe and in a larger population may prove to be clinically significant.

\section{Compliance with ethical standards}

\section{Conflict of interest}

All Authors declare no conflict of interest.

\section{Funding}

The ASSERT database has been developed and established through funds provided by Industry (Spectrum Technology UK) and ESPRC grants.

\section{Acknowledgements}

We thank Mr Jim Westwood and Mr Chris Schiel from Spectrum Technology for their support. Mr Nathan Bentley of twotwentyseven London Ltd - a creative digital agency developed the ASSERT platform following the direction of Professor Nicola Maffulli and Mrs Gayle Maffulli.

We thank all the clinicians recruiting participants onto the ASSERT database and the participants of ASSERT. Professor Nicola Maffulli developed the concept of ASSERT.

\section{Ethical approval}

All procedures performed in this study involving human participants were in accordance with the ethical standards of the institutional and/or national research committee and with the 1964 Helsinki Declaration and its later amendments or comparable ethical standards.

\section{Informed consent}

Informed consent was obtained from all individual participants included in the study.

\section{References}

1. Murphy RJ, Carr AJ. Shoulder pain. BMJ Clin Evid. 2010;07: 1107:1-37.

2. Refior H, Krodel A, Melzer C. Examination of the pathology of the rotator cuff. Arch Orthop Trauma Surg. 1987;106:301-308.

3. Uhthoff HK, Loehr JW. Calcific tendinopathy of the rotator cuff: pathogenesis, diagnosis and management. J Am Acad Orthop Surg. 1997;5:183-191.

4. De Carli A, Pulcinelli F, Delle Rose G, Pitino D, Ferretti A. Calcific tendinitis of the shoulder. Joints. 2014;2(3):130-113.

5. Gerdesmeyer L, Wagenpfeil S, Haake M, Maier M, Loew M, Wortler K, et al. Extracorporeal shock wave therapy for the treatment of chronic calcifying tendonitis of the rotator cuff: a randomised controlled trial. JAMA. 2003;290:7-10

6. Rebuzzi E, Coletti N, Schiavetti S, Giusto F. Arthroscopy surgery versus shockwave therapy for chronic calcifying tendinitis of the shoulder, J. Orthop. Traumatol. 2008;9(4):179185. http://dx.doi.org/10.1007/s10195-008-0024-4.

7. Suzuki K, Potts A, Anakwenze, A Singh O. Calcific tendinitis of the rotator cuff: management options. J Am Acad Orthop. Nov 2014;22(11):707-717.

8. De Palma AF, Kruper JS. Long-term study of shoulder joints afflicted with and treated for calcific tendinitis, Clin. Orthop. 1961;20:61-72.

9. Rompe JD, Rumler F, Hopf C, Nafe B, Heine J. Extracorporal shockwave therapy for calcifying tendinitis of the shoulder. Clin Orthop. 1995;321:196-201. 
10. Hsu CJ, Wang DY, Tseng KF, Fong YC, Hsu HC, Jim YF. Extracorporeal shockwave therapy for calcifying tendinitis of the shoulder, J Shoulder Elb Surg. 2008;17(1):55-59.

11. loppolo F, Tattoli M, Di Sante L, Venditto T, Tognolo L, Delicata $\mathrm{M}$, et al. Clinical improvement and resorption of calcifications in calcific tendinitis of the shoulder after shock wave therapy at 6 months' follow-up: a systematic review and metaanalysis, Arch. Phys. Med. Rehabil. 2013;9(9):1699-1706.

12. Louwerens JK, Sierevelt IN, van Noort A, van den Bekerom MP. Evidence for minimally invasive therapies in the management of chronic calcific tendinopathy of the rotator cuff: a systematic review and meta-analysis. J Shoulder Elb Surg. 2014 Aug;23(8):1240e1249.

13. Rompe JD, Zoellner J, Nafe B. Shock wave therapy versus conventional surgery in the treatment of calcifying tendinitis of the shoulder. Clin Orthop Relat Res. 2001;387:72-82.

14. Wang CJ, Yang KD, Wang FS, Chen HH. Wang JW. Shockwave therapy for calcific tendinitis of the shoulder: a prospective clinical study with two-year follow-up. Am J Sports Med. 2003;31:425-426.

15. Cacchio A, Paoloni M, Barile A, Don R, de Paulis F, Calvisi V, et al. Effectiveness of radial shock-wave therapy for calcific tendinitis of the shoulder: single-blind, randomized clinical study. Phys Ther. 2006;86(5):672-682.

16. Daecke W, Kusnierczak D, Loew M. Long-term effects of extracorporeal shockwave therapy in chronic calcific tendinitis of the shoulder. J Shoulder Elbow Surg. 2002;11(5):476-480.

17. Jakobeit C, Winiarski B, Jakobeit S, Welp L, Spelsberg G. UItrasound-guided, high-energy extracorporeal shock-wave treatment of symptomatic calcareous tendinopathy of the shoulder. ANZ J Surg. 2002;72(7):496-500.

18. Krasny C, Enenkel M, Aigner N, Wlk M, Landsiedl F. Ultrasound-guided needling combined with shock-wave therapy for the treatment of calcifying tendonitis of the shoulder. J Bone Joint Surg Br. 2005;87(4):501-507.

19. Pan PJ, Chou CL, Chiou HJ, Ma HL, Lee HC, Chan RC. Extracorporeal shock wave therapy for chronic calcific tendinitis of the shoulders: a functional and sonographic study. Arch Phy Med Rehab. 2003;84(7):988-993.

20. Peters J, Luboldt W, Schwarz W, Jacobi V, Herzog C, Vogl TJ. Extracorporeal shock wave therapy in calcific tendinitis of the shoulder. Skeletal Radiol. 2004;33(12):712-718.

21. Pleiner J, Crevenna R, Langenberger $\mathrm{H}$, Keilani M, Nuhr M, Kainberger $F$, et al. Extracorporeal shockwave treatment is effective in calcific tendonitis of the shoulder. A randomized controlled trial. Wien Klin Wochenschr. 2004;116(15-16):536-541.

22. Rompe JD, Burger R, Hopf C, Eysel P. Shoulder function after extracorporal shock wave therapy for calcific tendinitis. J Shoulder Elbow Surg. 1998;7(5):505-509.

23. Wang CJ, Ko JY, Chen HS. Treatment of calcifying tendinitis of the shoulder with shock wave therapy. Clin Orthop. 2001; 387:83-89.

24. Spindler A, Berman A, Lucero E, Braier M. Extracorporea shock wave treatment for chronic calcific tendinitis of the shoulder. J Rheum. 1998;25(6):1161-1163.
25. Jurgowski W, Loew M, Cotta H, Staehler G. Extracorporeal shock wave treatment of calcareous tendonitis of the shoulder. J Endourol. 1993;7(Suppl 1):13-17.

26. Loew M, Daecke W, Kusnierezak D, Rahmanzadeh M, Ewerbeck V. Shock wave application in calcifying tendinitis of the shoulder: prediction of outcome by imaging. Arch Orthop Trauma Surg. 2000;120:43-48.

27. Maffulli G, Hemmings S, Maffulli N. Assessment of the Effectiveness of Extracorporeal Shock Wave Therapy (ESWT) For Soft Tissue Injuries (ASSERT): An Online Database Protocol. Transl Med @ UniSa. 2014;10:46-51.

28. Padulo J, Oliva F, Frizziero A, Maffulli N. Muscles, Ligaments and Tendons Journal - Basic principles and recommendations in clinical and field science research: 2016 update. MLTJ. 2016;6(1):1-5.

29. Gerdesmeyer L, Wagenpfeil S, Haake M, Maier M, Loew M, Wörtler K, et al. Extracorporeal Shock Wave Therapy for the Treatment of Chronic Calcifying Tendonitis of the Rotator Cuff: a randomized controlled trial. JAMA. 2003;290:2573-2580.

30. EuroQol-Group. EuroQol: a new facility for the measurement of health related quality of life. Health Policy. 1990;16:199-208.

31. Scott J, Huskisson EC. Graphic representation of pain. Pain. 1976;2:175-184.

32. Pransky G Feuerstein M, Himmelstein J, Katz JN, VickersLahti M. Measuring functional outcomes in work-related upper extremity disorders. JOEM. 1997;39:1195-1202.

33. Ioppolo F, Tattoli M, Di Sante L, Atanasi C, Venditto T, Servido $M$, et al. Extracorporeal shock-wave therapy for supraspinatus calcifying tendinitis: a randomized clinical trial comparing two different energy levels. Phys Ther. 2012 Nov;92(11):13761385.

34. Lee SY, Cheng B, Grimmer-Somers K. The midterm effectiveness of extracorporeal shockwave therapy in the management of chronic calcific shoulder tendinitis. J Shoulder Elbow Surg. $2011 \mathrm{Jul} ; 20(5): 845-854$.

35. Loew M, Daecke W, Kusnierczak D, Rahmanzadeh M, Ewerbeck $V$. Shock-wave therapy is effective for chronic calcifying tendinitis of the shoulder. J Bone Joint Surg Br. 1999 Sep;81 (5):863-867.

36. Dubs B. Efficacy and economical aspects: comparison ESWT versus alternate therapies in the treatment of calcifying tendinitis, in: $6^{\text {th }}$ international Congress of the International Society for Musculoskeletal Shockwave Therapy. Orlando. 2003.

37. Haake M, Rautmann T, Wirth. Assessment of the treatment costs of extracorporeal shock wave therapy versus surgical treatment for shoulder diseases. Int J Technol Assess Health Care. 2001;17;4:612-617.

38. Eid J. Economic aspects in the treatment of tendinosis calcarea of the shoulder, in: $9^{\text {th }}$ International Congress of the International Society for Musculoskeletal Shockwave Therapy. Rio de Janeiro, Brazil. 2006.

39. NICE Extracorporeal shockwave lithotripsy for calcific tendonitis (tendinopathy) of the shoulder. Interventional procedures guidance [IPG21] Published date: November. 2003. https://www.nice.org.uk/guidance/ipg21/chapter/1-Guidance. 